\title{
Incidence of Legionnaires' disease in a district general hospital
}

\author{
A. R. AtKinson* \\ M.B., M.R.C.P. \\ S. K. R. ClARKE $\dagger$
M.D., F.R.C.Path.
}

\author{
R. J. WHITE* \\ M.D., F.R.C.P.
}

A. D. BLAINEY*

M.B., M.R.C.P.

*Frenchay Hospital, and $\uparrow$ Public Health Laboratory, Bristol

\section{Summary}

In order to assess the incidence of Legionnaires' disease in a district general hospital, 90 consecutive patients with pneumonia seen over a 3-year period were investigated. Only 2 patients were found to have Legionnaires' disease, indicating that it is not a frequent cause of pneumonia in the Bristol area.

\section{Introduction}

An outbreak of pneumonia at the Pennsylvania State American Legion Convention in Philadelphia in 1976 was subsequently called Legionnaires' disease (Fraser et al., 1977) and was later identified as being due to a Gram-negative bacterium (McDade et al., 1977), which has been named Legionella pneumophila. Since then, other small epidemics and sporadic cases have been described both in the United States and the United Kingdom. It has been suggested that Legionnaires' disease could be a frequent but unidentified cause of pneumonia and in order to determine its incidence in the Bristol area, England, the sera of patients with pneumonia seen at one hospital over a 3-year period (19771979) have been examined for antibodies to $L$. pneumophila.

\section{Methods}

Ninety consecutive patients with primary pneumonia acquired outside hospital were studied; 54 were male and their ages ranged from 15 to 90 years. Investigations included culture of sputum when available and examination of blood for complement fixing antibodies to respiratory viruses, Mycoplasma pneumoniae, $\mathrm{Q}$ fever and psittacosis. Where possible, paired blood samples were obtained but if the illness was of more than 3 weeks' duration on admission, a single convalescent specimen was examined. The sera have been examined in retrospect for antibodies to $L$. pneumophila by the indirect immunofluorescent test using PHLS Standards

Requests for reprints: Dr R. J. White, Department of Medicine, Frenchay Hospital.
Laboratory formalized yolk sac preparation of the Pontiac strain and conjugated anti-human globulin (Wellcome).

\section{Results}

A pathogen was identified in 40 of 90 patients (Table 1). Of the remaining 50 patients, sera were

\begin{tabular}{lr}
$\begin{array}{l}\text { TABLE 1. Pathogens identified in } \\
\text { out of } 90 \text { patients admitted to hospital } \\
\text { with primary pneumonia }\end{array}$ \\
\begin{tabular}{lr}
\multicolumn{2}{c}{} \\
Streptococcus pneumoniae
\end{tabular} \\
Strep. viridans (on blood culture) \\
Staphyloccoccus aureus \\
Klebsiella pneumoniae & 2 \\
Mycoplasma pneumoniae & 2 \\
Q Fever & 12 \\
Psittacosis & 3 \\
Influenza A and B & 2 \\
Parainfluenza & 4 \\
Respiratory syncytial virus & 1 \\
\hline
\end{tabular}

available for examination for antibodies to $L$. pneumophila in 31 , and 2 patients were identified as having Legionnaires' disease.

A man aged 38 years, who was admitted to hospital in December 1977 with a segmental pneumonia in the right upper lobe, had a rise in titre to L. pneumophila from less than 2 to 128 over 16 days. He made an uneventful recovery during treatment with ampicillin.

The second patient was also a previously healthy man aged 65 years. He was admitted in August 1978 gravely ill with a left upper lobe pneumonia. He died 11 days after admission and at the time of death had received one week's treatment with erythromycin. The titre of antibody to $L$. pneumophila had risen from 32 to 128 over 6 days.

Neither of these patients had been abroad recently. None of the remaining 29 patients had antibodies to L. pneumophila at a titre of 16 . 


\section{Discussion}

McDade et al. (1977) estimated that 1-2\% of pneumonia in the United States might be due to Legionnaires' disease. Foy et al. (1979) examined sera from 354 adults and 146 children with pneumonia in Seattle between 1963 and 1975, only $16 \%$ of whom were ill enough for admission to hospital. Five adults and no children had serologically proved Legionnaires' disease. Renner et al. (1979) examined retrospectively sera from 463 patients of all ages admitted to hospital with pneumonia in Iowa between 1972 and 1977; 4.5\% were found to have been infected with $L$. pneumophila. The only study in the U.K. has been that of Macrae, Appleton and Laverick (1979) who found that of $\mathbf{4 0 2}$ patients from the North and Midlands, $41(10 \%)$ had serological proof of infection. These patients who were investigated because Legionnaires' disease was suspected were probably more severely ill than many of the patients in the present study.

Of the 90 patients seen over this 34-month period (1977-1979) only 2 patients had Legionnaires' disease. It is difficult to express these numbers as a percentage of the total since sera were not available in 20 of the patients, but in the 70 patients where satisfactory samples were obtained the incidence was $2 \cdot 8 \%$.

Miller (1979) has suggested that in Nottingham, Legionnaires' disease is as common as pneumococcal and mycoplasmal pneumonia, but the authors' experience in Bristol indicates that it is an uncommon cause of pneumonia. It seems likely that further studies will show this variation in the geographical incidence of sporadic cases.

\section{Acknowledgements}

We would like to thank Dr K. J. Harrison for the bacteriological examinations and Dr A. D. Macrae of the Public Health Laboratory, Nottingham, and the staff of the Bristol Public Health Laboratory for the Legionella pneumophila antibody estimations.

\section{References}

Foy, H.M., Broome, C.V., Hayes, P.S., Allan, I., CoOney, M.K. \& Tobe, R. (1979) Legionnaires' disease in a prepaid medical care group in Seattle 1963-75. Lancet, i, 767.

Fraser, D.W., Tsai, T.R. (sic), Orenstein, W., Parkin, W.E., Beecham, H.J., Sharrar, R.G., Harris, J., Mallison, G.F., Martin, S.M., McDade, J.E., Shepard, C.C., BRachman, P.S. \& Field InVestigation TEAM (1977) Legionnaires' disease. Description of an epidemic of pneumonia. New England Journal of Medicine, $297,1189$.

McDade, J.E., Shepard, C.C., Fraser, D.W., Tsai, T.R. (sic), Redus, M.A., DOWDle, W.R. \& LABORATORY INVESTIGATION TEAM (1977) Legionnaires' disease. Isolation of a bacterium and demonstration of its role in other respiratory disease. New England Journal of Medicine, $297,1197$.

Macrae, A.D., Appleton, P.N. \& Laverick, A. (1979) Legionnaires' disease in Nottingham, England. Annals of Internal Medicine, 90, 580.

Miller, A.C. (1979) Early clinical differentiation between Legionnaires' disease and other sporadic pneumonias. Annals of Internal Medicine, 90, 526.

RenNer, E.D., Helms, C.M., Hierholzer Jr, W.J., Hall, N., Wong, P.W., VINer, J.P., Johnson, W. \& HAUSTER Jr, W. J. (1979) Legionnaires' disease in pneumonia patients in Iowa. A retrospective seroepidemiologic study, 1972-1977. Annals of Internal Medicine, 90, 603. 